\title{
LAS INSUFICIENCIAS DE LOS PROGRAMAS DE CLASE DE LENGUA ESPAÑOLA: EL CASO DE INTEC, LA UASD Y EL ISFODOSU
}

The shortcomings of the programs of Spanish language class: the case of INTEC, UASD and ISFODOSU

Fari Rosario*

Resumen: en este artículo se analizan aspectos significativos relacionados con el programa de clase de Lengua Española de tres universidades reconocidas de República Dominicana: la Universidad Autónoma de Santo Domingo (UASD), el Instituto Tecnológico de Santo Domingo (INTEC) y el Instituto Superior de Formación Docente Salomé Ureña (ISFODOSU). La finalidad de este trabajo es analizar dichos programas y describir su alcance y sus contenidos a la luz de la lingüística cognitiva y el enfoque de la metáfora. Se describe la naturaleza de la lengua española, así como la importancia de la categorización lingüística y cómo desarrollar competencias metafóricas en los alumnos y alumnas.

La investigación es exploratoria, con un enfoque fundamentalmente cualitativo y con una muestra intencional no probabilística. Las unidades de análisis son los tres programas de clase de las universidades elegidas. La metodología empleada favorece el análisis estructural de los componentes que conforman el género denominado programa de clase y sus partes constitutivas: fundamentación de la asignatura, descripción de la asignatura, propósitos, contenidos. Los hallazgos más notorios indican que la mayor deficiencia de

Profesor del INTEC y director de Publicaciones Científicas. Correo electrónico: ramon.rosario@intec.edu.do 
los programas de clase de las universidades analizadas no está en el qué y cómo enseñan, sino en que dichos programas no rebasan la visión del mero enfoque estructuralista y la enseñanza de conceptos. Se infiere, pues, que las reformas curriculares más que proponer contenidos deben apoderarse del enfoque lingüístico cognitivo, ya que el individuo no solo procesa información sino que la interpreta y la reproduce a través de situaciones comunicativas diversas.

Palabras clave: enseñanza del español, programa de clase, categorización lingüística, lingüística cognitiva, metáfora.

Abstract: this article discusses significant aspects related to the outline of the course Spanish language as taught in three recognized universities in Dominican Republic: the Universidad Autónoma de Santo Domingo (UASD for its Spanish acronym, but "Autonomous University of Santo Domingo" were it to be translated), the Instituto Tecnológico de Santo Domingo (INTEC for its Spanish acronym, but "Technological Institute of Santo Domingo") and the Instituto Superior de Formación Docente Salomé Ureña (ISFODOSU and "Higher Learning Institute for Teachers" respectively). The purpose of this paper is to analyze the outline and describe its scope and content drawing from a cognitive and linguistic approach to metaphors. The nature of the Spanish language, the importance of linguistic categorization and how to develop metaphorical skills in students is described.

The research is exploratory, with a largely qualitative approach and a non-probabilistic intentional sample. The units of analysis are three course outlines of the chosen universities. The methodology employs a structural analysis of the components that make up the course outline and its constituent parts: foundation of the course, course description, purpose, and content. The most notable findings indicate that the greatest deficiency of the outlines analysed is not what and how they are taught, but that such programs engage with a structuralist approach and teaching concepts. It 
therefore follows that rather than proposing reforms of the curricular content, these should seize a cognitive linguistic approach -individuals not only processes information but interprets and reproduces it through distinct situations.

Keywords: Spanish teaching program, class, linguistic categorization, cognitive linguistics, metaphor.

\section{Introducción}

La enseñanza del español forma parte del ciclo de los estudios generales de las universidades dominicanas. Todo cuanto puede ser dicho, deseado o representado en cualquier esfera de la vida humana puede ser expresado a través del lenguaje. De modo que el dominio de la lengua y de los códigos de comunicación son atributos esenciales de un profesional en cualquier rama del saber. Se comprende, pues, que cuando el estudiante ingresa a una universidad tiene la oportunidad de afianzar los conocimientos de su lengua y, al mismo tiempo, de aprender las estrategias que facilitan el procesamiento de la información, la producción textual y el desarrollo del pensamiento.

El análisis que aquí se propone no es de carácter histórico ni descansa en la filosofía particular de las instituciones objeto de estudio. Tan solo analiza los propósitos del programa de clase de lengua española y sus contenidos según las modalidades de las tres universidades ${ }^{1}$ analizadas.

1 Una salvedad necesaria: se analizan estas tres universidades porque ofrecen (o han ofrecido alguna vez) maestrías en Lingüística Aplicada a la Enseñanza del Español. De hecho, son las únicas universidades dominicanas que han prestado atención a la lingüística como disciplina científica. 
La finalidad de este trabajo es analizar dichos programas y describir su alcance y sus contenidos a la luz de la lingüística cognitiva y sus avances más recientes. El punto de partida es la convicción de que el programa de clase de lengua española tiene una importancia trascendental, ya que es el mapa que orienta la búsqueda de nuevas competencias y su posible desarrollo. Los profesionales de hoy no son individuos pasivos, sino actores que interactúan continuamente a través de la tecnología de la comunicación. Esto les permite redimensionar su visión del mundo y su lenguaje, compartir su experiencia y valorar los saberes de los demás.

Esta indagación es una amplia reflexión teórica. Vale apuntar que la investigación es exploratoria, con un enfoque fundamentalmente cualitativo y con una muestra intencional no probabilística. Las unidades de análisis son los tres programas de clase de las universidades elegidas. La metodología empleada favorece el análisis estructural de los componentes que conforman el género denominado programa de clase y sus partes constitutivas: fundamentación de la asignatura, descripción de la asignatura, propósitos, contenidos.

\section{Algunos antecedentes. Situación de la enseñanza de la lengua española a nivel superior en República Dominicana}

En la década del ochenta comienzan las reflexiones sistemáticas sobre la naturaleza y los fines de la educación superior. En República Dominicana no existe un currículo de Lengua Española para el Nivel Superior. No obstante, existe un Plan Decenal de Educación Superior 2008-2018 que acentúa, como línea general, la necesidad y la urgencia de que se haga una reforma curricular y, más aún, de que esta logre la transformación significativa de la educación universitaria. Este Plan define la calidad en estos términos: "La educación superior de calidad debe ser entendida como la vía para que la persona desarrolle, en términos de competencias, las actitudes, los conocimientos, las capacidades, las habilidades y destrezas que le 
permitan alcanzar autonomía a nivel personal y profesional".... (Plan Decenal de educación superior 2008-2018: 103).

Sin embargo, este documento institucional no dice ni explica los pasos para lograr el desarrollo sostenido de la calidad educativa por áreas del saber; tampoco describe las competencias que conviene desarrollar, ni describe los enfoques lingüísticos más apropiados para lograr tales fines.

Aún los periódicos de República Dominicana y los informes de instituciones extranjeras siguen afirmando que los jóvenes que ingresan a la universidad tienen deficiencias en las matemáticas, en la lectura comprensiva y en la producción de textos coherentes y significativos.

El Plan mencionado anteriormente acentúa y privilegia la educación a través de herramientas tecnológicas mediante el uso continuo de la tecnología de la información y la comunicación (TIC), pero no alude a los programas de clase vinculados a las matemáticas ni a la lengua española, etc. En realidad esta es la gran paradoja de carácter institucional, social y cultural.

\section{Marco teórico}

Según Matos Moquete (1999), la lingüística estructural fue la que elaboró una visión de la lengua como comunicación, puramente abstracta y formal, dejando de lado el contexto, las circunstancias y lo subjetivo. Esta visión ha permeado nuestra cultura educativa y los modos de concebir el programa de lengua española que debe enseñarse. El análisis real debe comenzar con la revisión del concepto de lengua que se plasma en los programas de clases y que, consciente o inconscientemente, manejan los profesores del nivel superior. En ese sentido, cabe la pregunta: ¿Lengua como sistema de signos abstractos? ¿Lengua como comunicación? ¿Lengua como un proceso de interconexión cognitiva vinculado al habla y a los textos escritos? ¿Conviene concebir la lengua como experiencia 
del mundo? Con estas preguntas se plantea el problema esencial que se analiza en este artículo.

La visión de los fundamentos del currículo para el área de la lengua española (1995) reconoce en su formulación las limitaciones y errores del enfoque de la enseñanza del español basado en el estructuralismo lingüístico:

La enseñanza tradicional se caracteriza por orientar la clase de lengua a partir de modelos de corrección en base a la lengua literaria y por privilegiar en los contenidos aspectos como la ortografía, las reglas gramaticales, el empleo de las palabras con apego a la forma y al significado aprobados por la Academia de la Lengua. Ese enfoque menosprecia los usos corrientes en la sociedad y desde luego, las prácticas múltiples de la comunicación lingüística.

El enfoque estructural, por su parte, enfatiza en la enseñanzaaprendizaje los conocimientos sobre la lengua como sistema abstracto, por encima de las comunicaciones concretas. Por eso, en el programa y en los libros de texto basados en este enfoque, hay poco espacio para las actividades de comunicación. En cambio, abundan los contenidos orientados hacia el conocimiento, la definición, la ilustración y la clasificación de aspectos como la oración, el léxico, los modificadores... (Fundamentos del currículo, 1995: 7)

Este enfoque tan celebrado, pero poco cuestionado en República Dominicana, reconoce que su punto de partida es una visible integración de disciplinas y saberes vinculados a la lingüística.

El enfoque funcional y comunicativo, que guía este diseño, se nutre de varias orientaciones teóricas y metodológicas en enseñanza de la lengua. (...)

Recoge [y] aprovecha la teoría y el análisis del discurso, la pragmática, la sociolingüística, la psicolingüística y las 
ciencias cognitivas; todas esas disciplinas reunidas en una versión remozada de la lingüística aplicada. (Fundamentos del currículo, 1995: 7)

Lo paradójico del caso es que cada una de las corrientes lingüísticas mencionadas en la cita anterior tiene una peculiar concepción del lenguaje y, por tanto, del conocimiento de los hablantes, por lo que resulta casi imposible integrar en una clase las cinco concepciones. Quizás este es el motivo por el cual el enfoque funcional y comunicativo se identifique más con el saber de la pragmática (el uso de la lengua) y con la sociolingüística (conocimiento de las diversas situaciones comunicativas). Hay otro componente digno de subrayarse: de las disciplinas mencionadas en la cita anterior las más olvidadas son las ciencias cognitivas. Una evidencia de esto es que en la bibliografía final del área curricular correspondiente a lengua española no aparece el nombre de ninguno de los lingüistas que se mencionan en este artículo como pilares y propulsores de la lingüística cognitiva a partir de la década de los ochenta y las décadas posteriores.

A partir de la década del noventa se puso en boga el enfoque funcional y comunicativo para la enseñanza de la lengua en la educación básica y secundaria en República Dominicana. De hecho, este es el enfoque que asume el Ministerio de Educación cuando lanza su reforma curricular en 1995. Según Marín (2004), el enfoque funcional y comunicativo

"significa, además, que los saberes acerca de la lengua y los textos se relacionan con sus aspectos comunicativos, es decir, que se la estudia en función de la utilización que hace el usuario y no solamente de la descripción que haga el gramático. Esto no significa abolir la gramática dentro del ámbito de los aprendizajes escolares, sino que implica colocarla en un lugar auxiliar al servicio de las necesidades comunicativas, y no en el lugar central, como único estudio posible de la lengua". (2004: 16) 
El problema de este enfoque está en su fundamento filosófico y epistémico, es decir, en su concepción de la realidad de un modo mecanicista y en su visible instrumentalización del lenguaje. A esto se suma su reduccionismo, pues todo lo reduce a la función predominante, puesto que, según sostienen sus defensores, "la finalidad primera de la lengua es la comunicación". Hoy se duda y se cuestiona esta visión puesto que los cognitivistas han demostrado que la finalidad primera de la lengua es crear redes semánticas (Croft y Cruse, 2004; Evans y Green, 2007; Geeraerts y Cuyckens, 2007; Ibarretxe-Antunano y Valenzuela, 2012a , citados por Ibarretxe-Antunano, 2013).

Incluso puede decirse que ni siquiera la gramática tiene una base meramente estructural o funcional, pues la gramática tiene un dominio cognitivo. (Langacker, 1989, citado por Cuenca \& Hilferty, 1999). De acuerdo con Alexopoulou (2014), la concepción de la gramática y los fenómenos gramaticales adquieren un nuevo sentido al ser tratados desde la perspectiva del texto, de los géneros textuales y los procesos de procesamiento de la información.

La nueva propuesta de diseño curricular para la enseñanza de la lengua en todos los niveles en República Dominicana, pondera y reconoce la importancia del discurso. De modo que en la comprensión y el "funcionamiento del discurso debe tomarse muy en cuenta el comportamiento comunicativo del hablante y que toda metodología de la enseñanza de la lengua ha de tener en cuenta" (Matos Moquete, 1999: 242). En realidad ¿qué significa esto? A mi modo de ver, la cita anterior pone de manifiesto tres aspectos relevantes:

1. La lengua no debe enseñarse como sistema, como forma conceptual (teoría del estructuralismo).

2. El punto de partida en la enseñanza lingüística no debe anclarse en la comprensión y la producción de textos o discursos (enfoque lingüístico textual y funcional) porque cada 
texto tiene su superestructura, su formalidad y su estilo argumentativo o retórico. Este enfoque, sin embargo, no toma en cuenta las circunstancias, ni el universo de la subjetividad o la rica experiencia de los hablantes y su visión del mundo.

3. La lengua tiene en su base la generación de significado y la creatividad; por tanto, la enseñanza tiene que ser creativa, innovadora, dialógica, integradora, cognitiva.

\subsection{Sobre el programa de clase de lengua española}

La enseñanza de la lengua aún en la actualidad presenta debilidades en aspectos fundamentales tales como: el para qué de la enseñanza, el cómo enseñar y a través de qué recursos estratégicos hacerlo. El problema también concierne a los manuales, a los libros que utilizan los profesores (la mayor de las veces de su autoría o de autores extranjeros, por lo que dichos textos no responden a nuestro contexto y necesidades); pero el mayor problema concierne al programa de clase de las universidades de República Dominicana. $\mathrm{Y}$, claro, esto es una generalización conceptual a partir de los casos analizados en este trabajo.

\subsection{El programa de clase}

A fin de cuentas, ¿cuál es la brújula que orienta la enseñanza de la lengua en una universidad? La respuesta razonable tendría que describir dos realidades:

a) El programa de clase de lengua española.

b) Los libros de texto (y manuales) que utilizan los docentes como recursos auxiliares durante el proceso.

Como se espera, se abordará el primer punto y no el segundo (el b), ya que no es uno de los objetivos de esta investigación. 
Desde la década del ochenta se viene enfatizando en el deterioro de la enseñanza del español y en la debilidad visible de los programas de clase, ya que, según Matos Moquete (1988: 432):

Es común entre profesores de lengua, investigadores e intelectuales, la apreciación de que existe un deterioro constante en el uso del español. Las causas que se citan son siempre las mismas: descuidos de la enseñanza por las deficiencias de los programas y el bajo nivel de los profesores. Ante esta situación, los remedios propuestos se limitan al proceso de enseñanza aprendizaje, tratando de modificar el comportamiento de los protagonistas principales: el profesor y el alumno. Sin embargo, esa tentativa de solución es parcial e insuficiente, si no se toman en cuenta los factores generales de la planificación lingüística, los cuales rebasan los marcos estrechos de las aulas.

Otro problema evidente es este: el conflicto entre la concepción o cosmovisión del profesor y el programa de clase ya que, casi siempre dicho programa es confeccionado y elaborado por lingüistas o profesores que le antecedieron en el tiempo. De modo que él tendrá sus reservas, su crítica y se sentirá un poco distante si el programa de clase le obstaculiza o no satisface su vuelo creativo. Este es un tema que implica una seria reflexión. Según Parkinson de Saz (1981: 354): "Un profesor, por regla general no puede cambiar su metodología de la noche a la mañana, porque ya ha salido alguna nueva teoría lingüística que parece interesante para la enseñanza. Tiene que cumplir unos programas, no puede deshacerse del material didáctico ya adquirido".

El profesor por tanto no solo interpreta como juez lo que dice el programa sino que puede permanecer todo el tiempo como un lector pasivo, sin tomar partido y sin cuestionar el fundamento mismo de dicho programa o, quizás, sin descubrir si su teoría del lenguaje está en consonancia con los contenidos y estrategias descritos en el programa de clase. 
Y se olvida algo importante de acuerdo con Matos Moquete (1989), el ideal de la clase de lengua española no debe ser procurar la uniformidad (que todo el mundo se comunique), sino que el ideal debe ser el sentido y la inteligibilidad de los signos realizados a la luz de las prácticas sociales y de las estrategias adecuadas a tales fines.

\subsection{Las estrategias metodológicas para la enseñanza del español}

Resulta imposible analizar el programa de clase sin abordar las estrategias para enseñar la lengua en el aula. Las estrategias metodológicas para enseñar hoy la lengua española en el aula universitaria deben desarrollar y fomentar la creatividad. El profesor debe estar consciente de que su enfoque del lenguaje como eje del condicionamiento o estímulo (base del conductismo y el estructuralismo) no es lo que debe primar, sino la creatividad verbal. En ese sentido, se parte del criterio contemporáneo de que el aprendizaje de la lengua no se da por Estímulo-RepuestaRefuerzo, sino por un principio general de creatividad y por la estructura cognitiva que desarrollan los seres humanos (Chomsky, 1991, 2005); en consecuencia, debe ser analizada no como un producto final y acabado, sino como un proceso abierto y en construcción (Puente, Poggioli y Navarro, 1989). En este proceso es importante situar y redefinir la figura del profesor que enseña el español como lengua materna.

Desde la perspectiva de la enseñanza del español con carácter multidisciplinario implica tomar conciencia plena del rol esencial que juega el profesor en el aula al momento de enseñar la lengua materna. Debe ser emprendedor y construir espacios dialógicos en virtud de la buena argumentación y a través de metáforas (más adelante se abordará este tema). De modo que el profesor debe 
ser dinámico y construir espacios dialógicos en virtud de la buena argumentación y el conocimiento de los procesos cognitivos. ${ }^{2}$

La metodología de enseñanza del español a nivel superior debe tomar en cuenta el enfoque multidisciplinario (gramática generativa, lingüística del texto, lingüística cognitiva) con tal de posibilitar la vinculación de las nuevas redes semánticas, el procesamiento de la información y en particular el desarrollo de las tareas cognoscitivas (Puente, Poggioli y Navarro, 1989).

¿Qué enseñar? Hoy el punto de partida es el texto o discurso, no la enseñanza de la gramática, ni el párrafo o las oraciones como unidades significativas de la lengua. Más allá de la retórica y de los diversos actos de habla, está el análisis semántico del discurso y sus posibilidades comunicativas.

\section{Los aportes de la lingüística cognitiva y su enfoque}

\subsection{La lingüística cognitiva y las estrategias discursivas}

La lingüística cognitiva ha contribuido a la pedagogía moderna aportando nociones claves, tales como "organización esquemática”, "memoria", "esquemas", "guiones" (scripts), o formas similares de organización del discurso (Schank y Abelson, 1977, citado por Van Dijk, 2012).

2 El profesor de Lengua Española debe conocer los intereses e inquietudes de sus alumnos, dialogar con ellos, pero más aún debe determinar qué piensan los alumnos de la asignatura y de su forma de enseñar. De acuerdo con Moore, Walsh y Rísquez (2012), el profesor debe planificar bien sus clases y saber que él es la fuente de una valiosa series de mensajes. En ese orden de ideas, estas autoras sugieren al profesor lo siguiente:

Planee la codificación de esos mensajes mediante un lenguaje, unas imágenes, unas ideas, unas metáforas que entiendan sus alumnas y alumnos. Transmita su mensaje de tal manera que ayude a captar su atención, maximizar sus oportunidades de comprender lo que les enseña, creer en ello y recordarlo. Cuando lo haga, compruebe periódicamente si sus estudiantes se mantienen atentos, si todavía "lo captan", si siguen absorbiendo y aprendiendo el contenido que les transmite. (Moore, Walsh y Rísquez 2012: 16). 
Esta corriente lingüística nace en la década del ochenta, en California, con George Lakoff y Ronal Langacker, ambos vinculados al generativismo chomskiano. Luego se suman importantes investigadores: Mark Johnson, Turner, Taylor, entre otros. Según Cuenca \& Hilferty (1999), esta lingüística explica y relaciona conceptos claves tales como: la categorización, la estructura semántica, la metáfora y la metonimia, la polisemia y las categorías radiales, la gramaticalización. Para estos dos autores la lingüística cognitiva se define así:

La lingüística cognitiva es una teoría lingüistica hasta cierto punto heterogénea por su propia naturaleza interdisciplinar e integradora. No obstante, es posible determinar un conjunto de ideas comunes sobre el lenguaje y la cognición que la configuran como paradigma. La lingǘstica cognitiva se sitúa, en primera instancia, entre las ciencias cognitivas (la psicología, la antropología, la inteligencia artificial, etc.) que se ocupan de los diferentes aspectos de la cognición humana. (Cuenca \& Hilferty, 1999: 14)

Esta corriente teórica no solo tiene una concepción singular de la cognición, sino también de la realidad mundanal, de la experiencia, de la corporeidad y de los elementos que intervienen en los actos de habla según las diversas situaciones comunicativas. De hecho, "la lingüística cognitiva adopta un punto de vista filosófico que Lakoff y Johnson han denominado experiencialismo o realismo experiencial, en contraposición al objetivismo (Johnson 1987, Lakoff 1987a, Lakoff \& Johnson 1980, citado por Cuenca \& Hilferty (1999: 15). Ambas concepciones, la objetivista y la experiencialista tienen su arraigo filosófico pero entre ambas existe una diferencia en torno a las características de la cognición. Pueden resumirse con las siguientes consideraciones:

1. Para los defensores del objetivismo, el pensamiento es una manipulación mecánica de símbolos abstractos, que adquieren su significado por correspondencia directa con el mundo exterior. Para los experiencialistas, el pensamiento es más que una 
manipulación de símbolos abstractos; presenta una estructura ecológica en el sentido de que la eficiencia en el procesamiento cognitivo depende de la estructura global del sistema conceptual, y no simplemente de operaciones entre símbolos aislados.

2. Como consecuencia de [lo dicho anteriormente], desde el punto de vista objetivista, la mente humana es un "espejo de la naturaleza”. El pensamiento es abstracto e independiente de las limitaciones del cuerpo humano, de su existencia perceptual y nerviosa. Por el contrario, para el experiencialista, el pensamiento - es decir, las estructuras que constituyen nuestros sistemas conceptuales- surge de la experiencia corpórea y tiene sentido según dicha experiencia. (cfr. Lakoff 1987a: 12-15, citado por Cuenca \& Hilferty, 1999: 15).

En definitiva, la lingüística cognitiva reconoce que la experiencia del ser humano es el núcleo que funda el lenguaje, así como los límites de la subjetividad y la experiencia corpórea de los hablantes al momento de producir significados o de interpretar un texto determinado. Cabe preguntarse: ¿acaso no está esta teoría lingüística alineada y muy acorde con la teoría de los Estudios Generales y la posible integración del saber disciplinario con la experiencia cultural de quien se forma en la universidad? La respuesta constituye el tema de otro artículo que está por escribirse.

Hay que subrayar de igual modo los aportes que ha hecho la didáctica contemporánea, la cual pone mucho énfasis en las fases esenciales del diseño didáctico y en la implicación de las estrategias cognitivas para enseñar a aprender y a pensar. De acuerdo con Estévez Nénninger (2005), en el proceso de enseñanza y aprendizaje intervienen dos grandes estrategias básicas: las estrategias organizativas y las estrategias cognitivas. De entrada, hay que apuntalar que una estrategia didáctica es un plan básico que orienta las acciones y los procedimientos que se llevan a cabo en el aula para conseguir un propósito con los alumnos. Las estrategias organizativas, por tanto, tienen como fin crear el clima, la situación 
y la atmósfera propicia para el aprendizaje. A través de estas se eligen las actividades tanto individuales como grupales y los modos de interacción. Las estrategias cognitivas, sin embargo, son las herramientas que ayudan a pensar y a construir la argumentación en el aula.

\subsection{Metáfora, cognición y contexto}

Los estudios lingǘsticos avanzaron mucho durante el siglo XX. De modo que el alcance y el funcionamiento de los mecanismos trópicos, o sea, de "traslación de sentido se han abordado desde la semiótica, la literatura, la filosofía, la retórica y la prágmática" (Casaliglia y Tusón, 2007: 336). Hasta hace poco solo se enfatizaba la función estética de la metáfora y su vínculo con la literatura y la retórica, pero a partir de los amplios estudios de Lakoff y Johnson (1986) se descubre su función cognitiva y su articulación con los procesos del pensamiento y la acción de la vida cotidiana:

Para la mayoría de la gente, la metáfora es un recurso de la imaginación poética, y los ademanes retóricos, una cuestión de lenguaje extraordinario más que ordinario. Es más, la metáfora se contempla característicamente como un rasgo solo de lenguaje, como de palabras más que de pensamiento o acción. Por esta razón, la mayoría de la gente piensa que pueden arreglárselas perfectamente sin metáforas. Nosotros hemos llegado a la conclusión de que la metáfora, por el contrario, impregna la vida cotidiana, no solamente el lenguaje, sino también el pensamiento y la acción. Nuestro sistema conceptual ordinario, en términos del cual pensamos y actuamos, es fundamentalmente de naturaleza metafórica. (Lakoff y Johnson, 1986: 39)

Se desprende que la metáfora tiene varias funciones (estética, cognitiva, persuasiva, focal). Para el análisis importa sobre todo la función cognitiva de la metáfora. De hecho, desde antiguo, uno de los 
filósofos occidentales más influyentes, Aristóteles, subrayó y reconoció el carácter cognoscitivo de la metáfora, pues ella "instruye y nos hace conocer" y este reconoció que la construcción de metáforas se debe al talento natural de las personas para "saber apreciar las semejanzas". (Véase a Casalmiglia y Tusón, 2007: 336). Pero lo cierto es que la metáfora es un proceso cognitivo que se da a través de la interconexión entre el pensamiento y las estructuras del lenguaje (Danesi, 2004).

Los mecanismos de producción de una metáfora son naturales y simultáneos con la necesidad de la comunicación y el contexto en el que se produce. Así, por ejemplo, se comprende cuando un estudiante dice "me quemé en el examen": (examen = prueba de fuego $=$ horno ardiente, por lo que se entiende que aquí el examen no es equivalente diagnóstico: hoy me hice el examen médico). Otros ejemplos, sin embargo, nos muestran la dimensión económica, sintética y experiencial de los polos magnéticos de quien apela al lenguaje figurado en acción: "Eres una lumbrera", "eres un león”, "eres una estrella", "eres una zorra".

Las metáforas se utilizan en toda clase de discursos: en el habla coloquial y en la literatura, en las explicaciones didácticas y en la exposición de temas científicos; en los artículos de opinión y en las declaraciones de los políticos; en las crónicas y los titulares de los periódicos. Y si esto es así ¿por qué no han de usarse en el aula?

La comprensión de la metáfora exige analizar algunos conceptos básicos que han sido resituados y redefinidos a partir de los nuevos enfoques del lenguaje como "espejo de la mente humana". Esta redefinición tiene como eje natural el universo de la multidisciplinariedad. Algunos conceptos nucleares, como cognición, contexto o interacción son redefinidos a la luz de la psicología cognitiva, de la lingüística cognitiva y el Estudio Crítico del Discurso (ECD, Van Dijk, 2012). Estos conceptos son indispensables para analizar y 
comprender el discurso y los eventos comunicativos. Tales conceptos están vinculados intrínsecamente a la práctica del docente, al discurso de los profesores de español y a su modo peculiar de transmitir conocimientos.

La noción de contexto que propone Van Dijk (2012) en su libro Contexto y discurso es fundamental para la propuesta que estamos planteando. Dicho autor subraya la tesis de que el contexto no puede ser entendido como una situación objetiva, ni como un escenario o ambiente social, sino como un constructo subjetivo, experiencial (y por tanto único) de los participantes del discurso. Los contextos por tanto están relacionados con nuestra estructura mental. "Los modelos mentales son las representaciones cognitivas de nuestra experiencia". (Van Dijk, 2012: 103). Estos modelos son per sé únicos, personales y subjetivos; los participantes no solo los activan ante una situación dada de comunicación, sino que son patrones básicos que inciden en la producción y la comprensión del discurso.

A diferencia de los enfoques "interpretativos" tradicionales sobre la comprensión del discurso, los modelos mentales también ofrecen un "punto inicial" para su producción: si las personas representan las experiencias diarias, así como también los eventos o situaciones en modelos mentales subjetivos, estos modelos forman al mismo tiempo la base para la construcción de la representación semántica de los discursos sobre dichos eventos... (Van Dijk, 2012: 100)

Los modelos contextuales o modelos mentales, tal como los concibe el autor citado en el párrafo anterior, son los que determinan el discurso, el texto o el acto de habla. Se infiere, pues, el contexto como eslabón cognitivo está presente en todos los eventos comunicativos. En este sentido, los modelos mentales no representan objetivamente los eventos tratados en un discurso, sino la manera como cada usuario del lenguaje interpreta o construye dichos 
eventos y el modo como estos modelos almacenan o procesan el discurso en la memoria episódica. (Van Dijk, 2012).

La metáfora (como frase) que se da por y en la conversación, como registro lingüístico que permea la vida cotidiana en todos sus ámbitos, exige un modelo mental de los usuarios del lenguaje. No puede hablarse de modelos mentales sin aludir a conceptos tales como subjetividad, percepción, experiencia, comunicación: todos son conceptos claves al momento de comprender y analizar la dimensión cognitiva de la metáfora. En suma, hay que subrayar que nuestras experiencias cotidianas son parte de nuestros modelos mentales o esquemas cognitivos.

La teoría de los modelos contextuales (o cognitivos) nos permite inferir que cada individuo, cada hablante, posee varias memorias: memoria episódica, "memoria racional" (Anderson, 1990b, citado por Van Dijk, 2012), memoria emocional (Goleman, 2000), memoria semántica (o conocimiento compartido social y culturalmente, Van Dijk, 2012). Conceptos que hay que tener muy pendientes al momento de diseñar un programa de clase, pero también de enseñarlo.

\subsection{El proceso de categorización lingüística y la enseñanza de la lengua}

El enfoque de la lingüística cognitiva privilegia el proceso de categorización lingüística de los seres humanos. El hombre categoriza a partir de las cosas que le rodean en el mundo, de lo que conoce y de lo que le preocupa. El lingüista y estudioso Bruner (2001) reconoce que

el mundo de la experiencia de cualquier hombre normal se compone de una enorme colección de objetos, acontecimientos, personas, impresiones que pueden enjuiciarse como diferentes. (...) El proceso de categorización comprende, si se quiere, un acto de invención. Una serie de 
objetos queda comprendida en la categoría "silla", una colección de determinados números se agrupa como potencia de dos, ciertas estructuras son casas pero otras son "garajes" (Bruner, 2001: 15-16)

El enfoque metodológico para la enseñanza de la lengua debe ser de carácter multidisciplinario, por lo que debe integrar los aportes de la lingüística cognitiva pero también los de la sociolingüística, la lingüística del texto y la semántica. El siguiente cuadro sinóptico sirve para identificar las líneas operativas y la evolución de los enfoques sobre el lenguaje y sobre la concepción profunda de las unidades comunicativas (el texto/discurso) que debe guiar una enseñanza de la lengua de corte vanguardista.

\begin{tabular}{|c|c|c|c|c|}
\hline & $\begin{array}{l}\text { GRAMÁTICA } \\
\text { TRADICIONAL }\end{array}$ & $\begin{array}{c}\text { LINGÜÍSTICA } \\
\text { ESTRUCTURAL }\end{array}$ & $\begin{array}{l}\text { GRAMÁTICA } \\
\text { GENERATIVA }\end{array}$ & $\begin{array}{l}\text { LINGÜÍSTICA } \\
\text { TEXTUAL }\end{array}$ \\
\hline $\begin{array}{l}\text { 1. Tipo de } \\
\text { gramática }\end{array}$ & $\begin{array}{l}\text { Normativa } \\
\text { (descriptiva) }\end{array}$ & Descriptiva & Predictiva & Descriptiva \\
\hline $\begin{array}{l}\text { 2. Concepto } \\
\text { clave }\end{array}$ & Palabra & Signo/constituyente & Oración & Texto/discurso \\
\hline $\begin{array}{l}\text { 3. Centro de } \\
\text { análisis }\end{array}$ & Parte de la oración & $\begin{array}{l}\text { Funciones/ } \\
\text { paradigma }\end{array}$ & Categoría/proceso & $\begin{array}{l}\text { Proceso } \\
\text { comunicativo }\end{array}$ \\
\hline 4. Conceptos & $\begin{array}{l}\text { Correcto/incorrecto, } \\
\text { partes de la oración, } \\
\text { oración simple y } \\
\text { compuesta (hipótaxis } \\
\text { y parataxis) }\end{array}$ & $\begin{array}{l}\text { Sincronía } \\
\text { Lengua/habla, signo, } \\
\text { sistema, estructura, } \\
\text { oposición, valor, } \\
\text { sintagma/paradigma, } \\
\text { nivel. }\end{array}$ & $\begin{array}{l}\text { Gramatical/agrama- } \\
\text { tical, competencia/ } \\
\text { actuación, oración, } \\
\text { transformaciones, } \\
\text { reglas, principios }\end{array}$ & $\begin{array}{l}\text { Pertinente/no perti- } \\
\text { nente, competencia } \\
\text { comunicativa, texto, } \\
\text { coherencia, cohesión, } \\
\text { progresión temática, } \\
\text { registro, tipo de texto }\end{array}$ \\
\hline $\begin{array}{l}\text { 5. Aplicación } \\
\text { didáctica }\end{array}$ & $\begin{array}{l}\text { Gramática normativa } \\
\text { (L1) } \\
\text { Gramática-traducción } \\
\text { (L2) }\end{array}$ & $\begin{array}{l}\text { Método audio-lingual } \\
\text { (L2) } \\
\text { Análisis contrastivo } \\
\text { (L2) }\end{array}$ & $\begin{array}{l}\text { Enfoque cognitivo } \\
\text { (L2) } \\
\text { Análisis de errores } \\
\text { e interlengua (L2) }\end{array}$ & $\begin{array}{l}\text { Enfoque comunicativo, } \\
\text { método funcional- } \\
\text { nocional (L2) } \\
\text { Tipologías textuales } \\
\text { (L1L2) }\end{array}$ \\
\hline $\begin{array}{l}\text { 6. Aportaciones } \\
\text { a la didáctica }\end{array}$ & $\begin{array}{l}\text { Primera descripción } \\
\text { de la lengua, análisis } \\
\text { de la norma }\end{array}$ & $\begin{array}{l}\text { Descripción ling. } \\
\text { sistemática, atención } \\
\text { a la lengua hablada }\end{array}$ & $\begin{array}{l}\text { Insistencia en el } \\
\text { aspecto creativo, } \\
\text { modelo coherente y } \\
\text { completo de análisis, } \\
\text { tratamiento innova- } \\
\text { dor de los errores. }\end{array}$ & $\begin{array}{l}\text { Enfoque globalizador: } \\
\text { intrerdisciplinariedad, } \\
\text { lengua en uso, atención } \\
\text { al conjunto }\end{array}$ \\
\hline
\end{tabular}

Fuente: Cassany, Luna y Sanz (2007).

El proceso de categorización lingüística intelectual, por tanto, debe ser integral, no en virtud de procurar un mero dato informativo 
ni concatenar un pool de conceptos. Dicho proceso implica analizar, comparar, asociar, sintetizar e interpretar sucesos, acontecimientos y discursos. En ese sentido, conviene recordar la idea planteada por Bruner (2001), sobre el proceso de categorización. Según él "toda conducta que implique la clasificación de objetos o sucesos sobre la base de indicadores seleccionados puede concebirse como conducta de categorización, ya sea perceptual o conceptual. La principal diferencia existente entre identificar un objeto visualmente accesible, como una 'manzana' y un estadista del siglo XIX como un "conservador" no reside en el proceso de clasificación o identificación, sino en los materiales o indicadores utilizados". (Bruner, 2001: 222).

El dominio de la metáfora está articulado a lo concreto, a lo visual, pero también a lo conceptual y al régimen de las ideas vinculadas al discurso.

Según Bruner (2001), al momento de categorizar los sujetos tienden a buscar "un criterio de verosimilitud para utilizar y evaluar los indicadores de categorización. Esto quiere decir que al tratar de diferenciar los ejemplares y no ejemplares de una categoría dada, como debemos hacer tan frecuentemente en la ciencia, la medicina y desde luego en la vida diaria, el sujeto, en ausencia de cualquier información, tenderá a fiarse de indicadores que le hayan parecido útiles en el pasado, se trate o no de una situación análoga" (Bruner, 2001: 227).

De modo que en la recepción de información que hace cada individuo está presente el criterio cognitivo de verosimilitud, pero también lo está en la producción e interpretación del discurso: uno tiende a fiarse de lo que resulta más familiar o próximo. En definitiva, podemos concluir que el uso de la metáfora es una estrategia próxima y relevante para hacer visible y fiable los grados más altos de abstracción del conocimiento humano así como de su construcción. Y esta es justamente la estrategia discursiva que necesitan dominar y plasmar los alumnos en su vida profesional y 
social. El proceso interno de categorización lingüística del alumno (esa realidad cognoscitiva que consiste en comparar, sintetizar, analizar, ordenar e interpretar la información y comprender textos) posteriormente se evidenciará cuando el alumno se dedique a investigar un tema o bien en su informe final de investigación.

\section{Análisis de la enseñanza de la lengua española a la luz del programa de clase de tres universidades dominicanas: INTEC, UASD e ISFODOSU}

\subsection{El caso de INTEC}

El diseño curricular de INTEC, cuya última reforma fue en 2010 (actualmente, mayo de 2015, está en proceso de reforma curricular) está dividido en tres ciclos importantes:

1. El ciclo propedéutico y de formación general

2. El ciclo formativo

3. Ciclo profesional

Como ha de esperarse, la lengua española se imparte en el primer ciclo. Este ciclo se caracteriza por su ambientación hacia lo cultural, lo identitario y lo internacional. Pero ¿cuál es la naturaleza y el propósito de la enseñanza de la lengua? Veamos. Vale acotar que este primer ciclo tiene tres módulos:

- Módulo 1: Inserción a la vida universitaria (12 créditos)

- Módulo 2: Perspectiva cultural e histórica (4 créditos)

- Módulo 3: Comunicación y razonamiento (23 créditos). En este tercer módulo se sitúan las dos asignaturas del ciclo completo: Comunicación en Lengua Española I y Comunicación en Lengua Española II. ¿En el modo de categorizar o denominar la asignatura puede leerse algo entre líneas? 
Vale la pena transcribir el macro-propósito de este módulo tres: "Desarrollo de las destrezas y habilidades necesarias para comunicarse de manera efectiva en forma oral y escrita, así como utilizar conceptos e ideas matemáticas para interpretar, representar, plantear y resolver situaciones de problemas". (Documentos 19: Reforma curricular 2010: 43).

De modo que se hace explícito que el propósito fundamental de la enseñanza de la lengua española en el INTEC es este:

La asignatura Comunicación en Lengua Española tiene como finalidad contribuir a la formación general de los estudiantes mediante el desarrollo de competencias intelectuales tales como la comprensión, la generalización, la clasificación, el análisis y la producción escrita. Para ello se emplean estrategias de lectura para la comprensión, la interpretación y el análisis de textos y el esquema de la organización de los mismos, la producción de resúmenes, de síntesis y de textos nuevos. La lectura de artículos científicos y de obras literarias, así como la representación ante sus compañeros de los diferentes actos de intercomunicación oral garantizan una formación integral y un desempeño exitoso en la vida profesional. (Documentos 19: Reforma curricular 2010: 47)

Como se notará de inmediato, no hay que ir muy lejos para uno percatarse de que conceptos como creatividad, experiencia del hablante, contextos de comunicación o recursos retóricos son términos que ni siquiera aparecen en la descripción y los párrafos citados anteriormente. Desde luego, tampoco se alude a las competencias cognitivas, estratégicas y menos aún a las competencias metafóricas. Pero debemos puntualizar algunos aspectos relevantes y significativos. La fundamentación o justificación del programa de Lengua Española de INTEC (en sus tres párrafos), habla de "habilidades", no de competencias: primer punto digno de cuestionarse y de analizarse en profundidad, puesto que no son conceptos equivalentes. 
El Diccionario de la Real Academia Española (2014) define el término habilidad como "capacidad o disposición para algo; gracia o destreza en ejecutar algo que sirve de adorno a la persona"... (RAE, 2014: 1150). El diccionario de lingüística de Theodor Lewandowski (2000) define el término competencia así:

Supuesto/abstracción de la lengua que se refiere al hablante ideal. Hipótesis básica de la gramática transformativa; capacidad lingüística del hablante de la lengua materna, su conocimiento interior... A la competencia pertenece la capacidad de formar cuantas frases se quieran y de entenderlas, de decidir sobre la identidad de dos enunciaciones y sobre la pertinencia o no pertinencia de una expresión en su propia lengua... (Lewandowski, 2000: 61)

Para ilustrar mejor la cita anterior, digamos que se puede ser habilidoso y no ser competente. Por ejemplo, puede tenerse habilidad o disposición para dibujar, mas no tener la capacidad o la aptitud para comunicar, con claridad y soltura, lo que se sabe sobre dibujo a través de la lengua materna. En suma, la competencia implica un conocimiento adecuado y pertinente de la lengua y de los modos particulares de organizar el pensamiento para la acción comunicativa.

En lo relativo a la Descripción de la asignatura, se hace evidente que el enfoque acentúa la dicotomía entre lengua oral y escrita; pero aún más: el propósito fundamental de la asignatura es analizar - este verbo aparece unas 6 veces- las unidades significativas y distintivas de la lengua, tales como la oración, el párrafo, la síntesis, etc... De modo que se hace evidente que lo que importa no es la lengua como proceso (como creación de cultura y símbolos diversos), sino la legua como mero producto. Esto muestra incluso una contradicción conceptual y perceptiva, pues la segunda estrategia del programa de Lengua Española I es concebida en estos términos: Prácticas del uso de lengua en forma procesual, en sus diferentes manifestaciones: oraly escrita. 
El primer propósito del programa reza así: "Comprender los aspectos cognitivos, procedimentales y actitudinales de la descripción para aplicarlos a la vida personal, académica y profesional". Como se notará, este propósito obedece tan solo a un acto de habla aislado y formal, hubiese sido más certero si dijera: comprender la dimensión cognitiva de los diversos géneros textuales y la dimensión intersubjetiva de los hablantes; luego, en el bloque de estrategias hay que decir cómo puede lograrse este propósito y mediantes cuáles recursos.

Según Cassany (2006), se enseña lengua para al menos leer y escribir con soltura y destreza. Dicho autor sostiene que leer y escribir no es algo uniforme u homogéneo, sino formas sociales e históricas que merecen un ejercicio crítico. No debemos olvidar que los géneros discursivos están ligados a tres funciones fundamentales para producir y comprender el discurso: función cognitiva, función interpersonal y función sociopolítica. (Gunnarsson, 1997, citado por Cassany, 2006). Lo importante es subrayar que la primera función es la cognitiva.

Dentro del bloque de estrategias de enseñanza del programa de Comunicación en Lengua Española I del INTEC (unas 13 estrategias en total) no se alude a los juegos de lenguaje e interpretación subjetiva de los hablantes en virtud de la comprensión de textos; de hecho, ni el bloque de contenidos ni las estrategias descritas abordan o subrayan conceptos claves como experiencia, la relación entre creación, símbolo y lenguaje, o la producción e interpretación de los procedimientos expresivos o retóricos. Esto último es de suma relevancia hoy, ya que la interacción social lo es todo.

En cuanto al programa de Comunicación en Lengua Española II, puede decirse que este sigue las mismas líneas de los contenidos, los propósitos y las estratégicas que se emplean en Lengua Española I.

A partir de lo dicho y mostrado anteriormente, resulta evidente que el enfoque de la legua es de carácter estructuralista, es decir, tradicional. Además, puede inferirse que en esta propuesta curricular 
y su modo de enseñar la lengua española no se da la integración de competencias en el acto mismo de la enseñanza; lo que dificulta, en términos lingüísticos, el desarrollo pleno de un sujeto crítico, con pensamiento estratégico y capaz de generar nuevos conocimientos a partir relaciones discursivas o semánticas. El programa no favorece el desarrollo de un sujeto con dominio de competencias hermenéuticas y competencias metafóricas, sino tan solo el desarrollo de algunas competencias básicas.

\section{$5.2 \mathrm{El}$ caso de la UASD}

A continuación analizamos los propósitos y los contenidos de Lengua Española Básica I (3.5 créditos) y Lengua Española Básica II de la Universidad Autónoma de Santo Domingo (UASD). Lo primero que llama la atención es que ambos programas, según dice una nota al margen, están en proceso de revisión desde 1994. Pero ¿qué significa que están en revisión? ¿Cuánto tiempo se tomará la revisión como tal?

La justificación o fundamentación de Lengua Española Básica I (Clave: Let. 011) se describe así:

Los cursos de Lengua Española Básica I y II proporcionan al estudiante técnicas y mecanismos indispensables para elevar el nivel de comprensión de la lengua oral y escrita e incrementar su capacidad de la comunicación y desarrollar habilidades para la redacción. (...) Estos cursos determinan el carácter funcional de la lengua y facilitan al estudiante, las herramientas necesarias para lograr un desenvolvimiento adecuado en la comprensión de las diferentes asignaturas de la carrera que cursa, y los fundamentos para el logro del éxito en el ámbito profesional y personal.

Si analizamos los elementos del texto citado, vemos que el macropropósito o foco de la asignatura es la redacción. Pero ¿de qué tipo es la redacción: personal, científica o artística? El mismo Cassany 
(1999) nos dice que existen diversos tipos de escritura según la necesidad de los hablantes y el contexto, tales como escritura personal, escritura funcional, escritura creativa, escritura expositiva y escritura persuasiva.

De modo que la finalidad de la enseñanza de la lengua en la UASD es la redacción y no el desarrollo de competencias comunicativas, intelectuales, socioculturales, así como de competencias culturales y cognitivas (al menos para pensar de un modo reflexivo y crítico ante la realidad). No se usa el concepto competencia, sino que se habla de "habilidades" y destrezas. Resulta evidente que el enfoque de la legua es de carácter estructuralista, tradicional, mecánico, funcional, memorístico y lineal. Nótese además que no habla de modelar experiencias, ni de construir conceptos en torno a la realidad sino que este programa habla de "herramientas necesarias para lograr un desenvolvimiento adecuado de los alumnos y alumnas: eso suena hasta un poco conductista y determinista; así es como se instrumentaliza la lengua, al decir de Matos Moquete (1999). Hay otros factores de suma relevancia. De entrada hay que subrayar que el programa tiene unos "Objetivos generales" (un tanto vagos, difusos y no cohesionados), pero no contiene los $o b$ jetivos específicos de la asignatura en cuestión. Contiene, según se nota, siete objetivos generales: uno de ellos, el número seis dice: "Manejar los recursos y mecanismos necesarios para enriquecer su disponibilidad". Además de vago, el objetivo no está delimitado conceptualmente, para eso basta preguntarse lo siguiente: ¿Qué tipos de recursos, cuáles mecanismos? ¿Cómo hacerlo?

Pero hay algo digno de reflexión: el programa contiene "Sugerencias metodológicas de evaluación", pero no describe las estrategias de enseñanza propias de la asignatura.

Este programa consta de seis unidades y se basa en tres bloques:

1. Objetivos

2. Comunicación y lenguaje

3. Sugerencias y actividades 
Como se notará de inmediato, en la tabla de los contenidos según las diversas unidades no aparecen los lineamientos claros relacionados con la metodología o las estrategias para que los profesores de Letras desarrollen los contenidos. El bloque que debe aludir a esta realidad conceptual en el programa se denomina, simple y llanamente, sugerencias $y$ actividades.

Hay que subrayar de nuevo el reduccionismo lingüístico que contiene este programa y es justo lo que da pie a mi crítica epistémica. Es decir: en el programa de Lengua Española I se hace demasiado énfasis en la comunicación lingüística y no lingüística, de hecho el término comunicación aparece 14 veces. El problema -y hay que subrayarlo- es que el lenguaje no solo es comunicación, sino que también es creación, energía, experiencia vinculada a un sistema de símbolos dinámicos y plurales. (El programa habla de lengua, pero hoy en día lo más apropiado es hablar de lenguaje. La lengua, siguiendo a De Saussure, es un signo abstracto, formal, con niveles; el lenguaje es percepción y representación de conductas verbales y no verbales). De modo que el lenguaje no solo funda las prácticas sociales sino que funda el macro-universo de la cultura y de la interacción humana. Esta es la herencia que debemos debatir, que hay que discutir y repensar continuamente.

La unidad III titulada: "El valor estructural de la lengua" contiene lo siguiente:

3.1.1. La palabra en el contexto. Elementos morfológicos.

3.2.1. Valor semántico de la palabra en el contexto. Connotación, denotación; sinonimia, antonimia, paronimia, homonimia, etc.

\subsubsection{Acentuación y puntuación.}

La metáfora debería figurar en el subacápite 3.2.1. Pero ya sabemos que para el enfoque estructuralista la metáfora se concibe como una desviación lexical. Además en esta parte de la unidad también debería abordarse la expresión lingüística de los sujetos hablantes, la comunicación según los contextos, no según los actos de habla 
(descripción, narración, argumentación y exposición). Lo cual también resulta cuestionable y digno de discusión, pues no solo la intencionalidad define un acto de habla sino también la estrategia que el hablante pone en marcha en la enunciación. De ahí que García Molina (2014) se refiera a estos conceptos no como actos de habla, sino como estrategias del discurso. Se comprende, pues, que las funciones del lenguaje y su dimensión cognitiva son inseparables. De lo dicho anteriormente se desprende que para entender la naturaleza de la metáfora y la función de los recursos retóricos es menester hacer una nueva lectura de los límites de la retórica, la enunciación y los géneros científicos o académicos.

El programa de Lengua Española II (Let. 012) contiene siete unidades, tiene la misma justificación y los mismos objetivos que el programa denominado Lengua Española I; solo varían algunos contenidos y algunos temas:

Unidad 1: El arte de la comunicación y de la redacción

Unidad 2: Estructura y desarrollo del párrafo (esto también aparece en Lengua I)

Unidad 3: El valor estructural de la lengua

Unidad 4: Los modos de expresión: La exposición

Unidad 5: Los modos de expresión: La descripción

Unidad 6: Los modos de expresión: La narración y el diálogo

Unidad 7: La oratoria

Es curioso: en el desarrollo de la unidad siete no se mencionan ni siquiera conceptos tales como persuasión, recursos retóricos, metáfora, comunicación cognitiva, memoria semántica. Para que no quepa la menor duda, transcribo los contenidos completos de esta unidad:

\subsubsection{Conceptos de oratoria.}

La oratoria y la dialéctica.

Estructura del discurso: introducción, desarrollo, contenido. Conclusión. 


\subsubsection{Cualidades del orador. La elocuencia. Conocimiento del auditorio.}

\subsubsection{Clases de discursos.}

En definitiva, los dos programas de enseñanza de Lengua Española de la UASD no están actualizados, no están a la altura ni en consonancia con los enfoques lingüísticos más recientes. Pero hay algo más crucial y delicado: el diseño del programa no contiene estrategias claras ni precisas para desarrollar la enseñanza de los contenidos, ya que los mismos no promueven las competencias de un modo integral. A esto se suma otro factor: los programas no acatan lo indicado por el diseño curricular dominicano al subrayar que la enseñanza de la lengua materna debe tener como punto de partida la situación particular de los hablantes. Y como es evidente, estos programas no responden a los desafíos de la sociedad de la información en la que vivimos. Por tanto, estos programa no son efectivos ni propicios para desarrollar las competencias cognitivas, procedimentales y metafóricas, como lo están haciendo las universidades más exigentes en la actualidad.

De lo dicho hasta aquí, se desprenden algunas conclusiones importantes:

- El análisis y la comprensión de los procedimientos expresivos o retóricos debe ser una unidad (o tema) de todos los programas de Lengua Española a nivel superior.

- Hay que abandonar el enfoque que socava la concepción estructuralista o formal de la lengua y asumir un enfoque sociolingüístico y cognitivo, de carácter constructivista para enseñar la lengua y las funciones del lenguaje.

- En definitiva, estos dos programas resultan deficientes para enseñar lengua hoy en día, ya que no desarrollan un sujeto con capacidad crítica, flexibilidad, con autonomía y con capacidad para construir discursos diversos. 


\subsection{El caso de la enseñanza de la Lengua Española en el ISFOSODU}

A continuación analizamos los propósitos y los contenidos concernientes a la enseñanza de la Lengua Española en el Instituto Superior de Formación Docente Salomé Ureña (ISFODOSU). De entrada hay que decir que la Licenciatura de Educación Básica tiene dos especialidades, la primera se denomina Lecto-escritura e iniciación a la matemática y la segunda, licenciatura en Educación Básica mención en Lengua Española y Ciencias Sociales. En este sentido, se imparten varias asignaturas vinculadas a la enseñanza de la lengua española y a las necesidades propias de la carrera, dentro de las cuales se mencionan las más relevantes:

- Lengua Básica I

- Lengua Básica II

- Didáctica de la Lengua Española

- Lengua Española y Desarrollo de Competencias

- Lengua y Literatura

El programa de Lengua Española Básica I contiene cinco unidades. La asignatura se describe en estos términos:

Esta asignatura enfatiza los procesos de exposición oral, comprensión lectora y producción escrita, vista desde una concepción socio-cultural de la lengua y los procesos de aprendizaje. De igual manera, ofrece a los estudiantes las estrategias pertinentes para la apropiación de la comprensión lectora, la expresión escrita y oral, así como la apropiación de las competencias lingüísticas con miras a lograr un docente capaz de comunicarse con efectividad en su desempeño profesional y social. Este programa pretende formar un sujeto con capacidad para usar la lengua adecuadamente en diferentes situaciones de comunicación, entendiendo la lengua como la base de todo conocimiento. Además, enfatiza la comprensión, interpretación y producción de textos orales y escritos. 
Si se analiza el párrafo anterior, se descubre que el verbo enfatiza(r) aparece dos veces; el propósito de la enseñanza de la lengua es la expresión oral y la compresión escrita; fijese que aunque apela al llamado enfoque socio-cultural de la lengua no aparecen conceptos claves como experiencia, contextualización, situación de los hablantes, comprensión del discurso.

Este programa de clase no contiene objetivos específicos (ni siquiera por unidad de contenidos), se enumeran algunas actividades y sugerencias ordinarias, pero en sí no está delimitado ni precisado lo relativo a la metodología que debe usarse. Para nuestra sorpresa, la Unidad 3 está dedicada al tema de "Estrategias cognitivas y metacognitivas para la comprensión". Se habla aquí del resumen, la síntesis, del mapa semántico y del mapa conceptual pero no se alude a la metáfora. Primera conclusión o inferencia: esta realidad patente confirma nuestra tesis de que los programas de clase de Lengua Española a nivel superior en República Dominicana no solo ignoran los conocimientos más avanzados y recientes de la lingüística sino que no llenan las expectativas y los requisitos de una educación basada en competencias diversas y complejas.

La descripción o justificación que concierne a Lengua Española II del ISFODOSU dice así: La asignatura está orientada a profundizar en la comprensión lectora y producción escrita como acciones fundamentales para la formación académica y profesional de los futuros docentes. Procura fortalecer el dominio y la apropiación de la lengua, con énfasis en la lectura critica y reflexiva y acciones escriturales. Asimismo propicia la autonomía del estudiante aplicando criterios de búsqueda y selección de la información con la finalidad de producir textos de manera coherente.

Si se analiza este párrafo, se notará que no aparece la palabra "competencia", tampoco se destacan conceptos esenciales desde nuestra perspectiva teórica, tales como experiencia, situación de los hablantes, contexto, expresión del cuerpo, competencia metafórica, competencia hermenéutica, categorización, estrategias cognitivas, etc. 
Este programa no solo contiene una discrepancia con relación al de Lengua Española I sino que hay una visible incongruencia metodológica, pues aquí cada unidad de contenidos tiene varios objetivos específicos, cosa que no tiene, reitero, el primero. Sin embargo, los expertos nos dicen que "es importante presentar los objetivos de la asignatura, los resultados previstos del aprendizaje y la descripción del programa con un lenguaje claro y sin ambigüedades". (Moore, Walsh y Rísquez, 2012: 44).

El programa de clase de Lengua Española y Desarrollo de Competencias es una continuidad de lo descrito en los dos casos anteriores, la descripción de la asignatura solo se cambian algunas palabras o sustantivos. Si se lee detenidamente y se analizan los tres párrafos que describen y justifican la asignatura, se descubre algo chocante: aunque la asignatura se denomina LENGUA ESPAÑOLA Y DESARROLLO DE COMPETENCIAS, no se alude explícitamente a la necesidad de diversificar y desarrollar competencias literarias, enciclopédicas, emocionales, cognitivas y competencias metafóricas. Esta asignatura tiene 3 créditos; una visible deficiencia es que solo se dedica tiempo a la teoría, no hay horas para la práctica, la expresión oral y la investigación lingüística.

En general, los contenidos son bastante vagos; cada unidad de contenido tiene dos y tres objetivos específicos. Otra paradoja digna de pensar: en este programa a diferencia de los que he descrito y analizado anteriormente, las estrategias metodológicas son más claras, precisas y focales; por ejemplo, la Unidad II, dedicada al tema de "Las competencias generales en el currículo de lengua", trae estas estrategias docentes y presentadas de este modo:

- Debate

- Dramatizaciones

- Exposiciones

- Trabajos grupales y colaborativos

- Ensayo reflexivo 
La incongruencia de estos datos y enfoques metodológicos de la lengua nos hace inferir algo notorio y preocupante: los programas de clase de Lengua Española del ISFODOSU no obedecen a una política curricular definida por la institución sino que son preparados por los diversos profesores de turno que tienen a cargo enseñar la asignatura. Lo dicho hasta aquí se aplica de igual modo a la asignatura denominada "Didáctica de la lengua Española", así como a la denominada "Lengua y Literatura".

Por lo que hay que derribar otro mito muy común y conocido: el problema no es que los estudiantes provengan de estratos sociales muy vulnerables o que tengan pocos referentes culturales, o aludir a los problemas de formación de los profesores (muchos no se actualizan y repiten las indicaciones de los manuales y los textos escolares). Es evidente que los problemas no son de aprendizaje, sino más bien de cómo se enseña la lengua a nivel superior y cómo se podría sacar el mejor provecho posible a través de la investigaciónacción y los enfoques lingüísticos más avanzados y recientes.

\section{Conclusión}

Dentro de cualquier país de habla hispana, la lengua española tiene un rol esencial, social y culturalmente importante. No se enseña la lengua para enseñar gramática, normativa o cómo redactar bien, sino con el propósito fundamental de que los profesionales desarrollen amplias y múltiples competencias discursivas y comunicativas para aprender a pensar, analizar y a comprender la realidad en la que viven. Todas las competencias se articulan y se desarrollan a través de la lectura, la producción de textos, el ejercicio de la síntesis, el resumen, la comparación, la comunicación oral estratégicamente planificada y las estrategias metacognitivas. Hay que sintonizar gradualmente con todas las competencias (lingüística, lexical, comunicativa, contextual, intelectual, pero también con la emocional, la enciclopédica, la metafórica, la procedimental, la literaria, la socio-cultural, entre otras) aunque los programas de clase 
de las universidades analizadas hacen más hincapié en el manejo de la lengua oral y en la redacción. El reto es pasar de niveles básicos a niveles más complejos y dinámicos.

Los hallazgos más notorios indican que la mayor deficiencia de los programas de clase de las universidades analizadas (INTEC, UASD e ISFODOSU) no está en el qué y cómo enseñan, sino en que dichos programas no rebasan la visión del enfoque estructuralista y la enseñanza de conceptos. Las grandes reformas curriculares, por tanto, más que proponer contenidos deben gestionar y dar a conocer el enfoque lingüístico cognitivo, ya que el individuo no solo procesa información sino que la interpreta y la reproduce en situaciones comunicativas diversas.

El enfoque de la lengua en los programas de clase debe rebasar e ir más allá del mero desarrollo de competencias básicas de la lengua (enfoque funcional y comunicativo) y difundir un enfoque que desarrolle un sujeto con capacidades múltiples para leer y producir textos, un sujeto con dominio de competencias hermenéuticas y competencias metafóricas y cognitivas. Además, no debe olvidarse que en la enseñanza de la lengua de cada profesor subyace su concepción o manera de entender el lenguaje, esta concepción también está salpicada de otras rémoras sociales y culturales que no permiten el desarrollo transparente de la lengua. Hay que desmontar el concepto que reduce la metáfora a una figura retórica, y conviene que los profesores y personas vinculadas al diseño curricular en la educación superior reflexionen sobre este tema a través de seminarios, tertulias y conferencias.

Los profesores no pueden entender y comprender la dimensión cognitiva de la metáfora si esta ni siquiera aparece dentro de los contenidos del programa de Lengua Española de las diversas universidades dominicanas analizadas.

Se evidencia que la lingüística cognitiva es una disciplina que integra y valora la experiencia de los hablantes y favorece siempre 
la sistematización y la proyección de los procesos cognitivos a gran escala, cuestión que, en definitiva, representa un salto cualitativo para cualquier programa de clase que pretenda enseñar la lengua materna a nivel de educación superior.

\section{Recomendaciones}

Una reforma curricular no solo implica revisar los programas de clase y saber cuáles son las necesidades empresariales del momento. El proceso también implica realizar varias jornadas de trabajo con expertos no solo en currículo y en pedagogía, sino en lingüística aplicada a la enseñanza del español. Es preciso tomar en cuenta la dimensión curricular pero también la dimensión social y cognitiva de la enseñanza de la lengua española en el siglo XXI. A continuación se desglosan las recomendaciones según el caso particular de cada universidad.

En el caso del INTEC, conviene alinear su enseñanza con el enfoque lingǘstico cognitivo (sobre todo por ser una universidad que valora mucho la ciencia y la tecnología); además debe hacerse visible la integración de las competencias y los contenidos de sus dos programas de clase.

En el caso particular de la UASD, hay que hacer una revisión urgente de los programas de enseñanza de la Lengua Española. De esto depende la formación lingüística y el futuro de muchos profesionales del país.

En el caso particular del ISFODOSU, hay que recordar que su punto de partida es la concepción socio-cultural de la lengua. De modo que todas las asignaturas concernientes a la enseñanza del español deben ceñirse a esta concepción y, de igual modo, los contenidos deben relacionarse con este enfoque. 


\section{Referencias}

Alexopoulou, A. (2014). El enfoque basado en los géneros textuales y la evaluación de la competencia discursiva. Recuperado de http://cvc.cervantes.es/ensenanza/biblioteca_ele/asele/pdf/ 21/21_0097.pdf

Bruner, J. (2001). El proceso de aprendizaje. Madrid: Narcea, S.A.

Casalmiglia Blacafort, H. \& Tusón Valls. (2007). Las cosas del decir: Manual de análisis del discurso. Barcelona: Ariel.

Cassany, D. (1999). La cocina de la escritura. Barcelona: Anagrama.

Cassany, D. (2006). Taller de textos: Leer, escribir y comentar en el aula. Barcelona: Paidós.

Cassany, D., Luna, M. \& Sanz, G. (2007). Enseñar lengua. Barcelona: Editorial Graó.

Chomsky, N. (1991). Lenguaje, sociedad y cognición. México, D. F.: Trillas.

Chomsky, N. (2005). Sobre democracia y educación (Vol. 1). Barcelona: Paidós.

Cuenca, M. y Hilferty, J. (1999). Introducción a la lingüística cognitiva. Barcelona: Ariel.

Danesi, M. (2004). Metáfora, pensamiento y lenguaje. Sevilla: Centro de Investigaciones sobre Vico/Editorial Kronos.

Estévez Nénninger, E. (2005). Enseñar a aprender: Estrategias cognitivas. Barcelona: Paidós.

Goleman, D. (2000). La inteligencia emocional. México, D. F.: Ediciones B.

Ibarretxe-Antunano, I. (2013). La lingüística cognitiva y su lugar en la historia de la lingüística. RESLA 26, 245-266. Recuperado 
de http://eds.a.ebscohost.com/eds/pdfviewer/pdfviewer? vid $=39 \&$ sid $=0144131 \mathrm{~b}-2305-45 \mathrm{ab}-\mathrm{beb} 3-433 \mathrm{af1} 12 \mathrm{ed} 37 \% 40$ sessionmgr4004\&hid $=4111$

Instituto Tecnológico de Santo Domingo (2010). Documentos 19: Reforma curricular 2010. Santo Domingo: Instituto Tecnológico de Santo Domingo.

Lakoff, G. \& Jhonson, M. (1986). Metáfora y vida cotidiana. Madrid: Cátedra.

Lewandowski, T. (2000). Diccionario de lingüística (5ta. Ed.). Madrid: Cátedra.

Marín, M. (2004). Lingüística y enseñanza de la lengua. Buenos Aires: Grupo editor AIQUE. Recuperado de http:/ /www.terras.edu. ar/aula/tecnicatura/4/biblio/4MARIN-Marta-CAP-1-Elenfoque-comunicacional-para-la-ensenanza-de-la-lengua.pdf

Matos Moquete, M. (1988). Palabras introductorias por un enfoque global de los problemas de la enseñanza de la lengua. Ciencia y Sociedad, 13(4), 432-436.

Matos Moquete, M. (1989). La cultura de la lengua en la conformación de nuestra Nación. Estudios Sociales, 22(75), 107-117.

Matos Moquete, M. (1999). La cultura de la lengua. Santo Domingo: Instituto Tecnológico de Santo Domingo.

Matos Moquete, M. (2002). El dominio de las competencias en el español universitario. Ciencia y Sociedad, 27(4), 566-577.

Matos Moquete, M. (2005). Estudios translingüísticos. Santo Domingo: Editora Nacional.

Moore, S. Walsh, G. \& Rísquez, A. (2012). Estrategias eficaces para enseñar en la universidad: Guía para docentes comprometidos. (Trad. de Pablo Manzano). Madrid: Narcea. 
Poggioli, L. \& Navarro, A. (1989). Psicología cognoscitiva: Desarrollo $y$ perspectivas. Caracas: McGraw-Hill Interamericana.

Real Academia Española. (2014). Diccionario de la lengua española (Tomo II). Madrid: Real Academia Española.

Secretaría de Estado de Educación Superior, Ciencia y Tecnología (SEESCyT). (2008). Plan decenal de educación superior 2008-2018. Santo Domingo: Secretaría de Estado de Educación Superior, Ciencia y Tecnología.

Van Dijk, T. (2012). Discurso y contexto. (Trad. Andrea Lizosain). Barcelona: Gedisa. 


\section{Fari Rosario}

Es candidato a doctor en Estudios del Español: Lingüística y Literatura por la Pontificia Universidad Católica Madre y Maestra (PUCMM); maestría en Lingüística Aplicada a la Enseñanza del Español por la Universidad Autónoma de Santo Domingo (UASD); licenciatura en Filosofía por la Pontificia Universidad Católica Madre y Maestra.

Ha publicado: El jabalí y otros microcuentos (2007); El coleccionista (2008); Polvo y olvido (2009); El discurso de la interioridady la condición bumana en Una rosa en el quinto infierno (breve ensayo, 2009); El columpio de los sonámbulos: Antología de minicuentos dominicanos (2010).

Líneas de investigación:

- Análisis del discurso político y sus metáforas

- El discurso científico y sus alcances lingüísticos

- La narrativa caribeña y lo real maravilloso

Correo electrónico: ramón.rosario@intec.edu.do

Recibido: 09-06-2015

Aprobado: 25-09-2015 
